\title{
Research on the Evolution of Placard Design During the Period of the Republic of China (1912-1937) in Shanghai
}

\author{
Zhan Huang ${ }^{1, *}$ \\ ${ }^{1}$ Academy of Fine Arts, Nanjing Xiaozhuang University, Nanjing, Jiangsu, China \\ *Corresponding author. Email: 418002146@qq.com
}

\begin{abstract}
The placard design in Shanghai during the Republic of China was a very important link of the modern design system in China. Since the early period of the Republic of China, some design styles combined with commercial behavior and introduced from the West began to appear and developed into an important advertisement form at that time. Through the analysis of the content, this paper studies the main types and functions of the placards during the Republic of China, and extracts the main developments and changes from the perspective of the evolution process. These are not only a review of the design content at that time, but also a perfection of the evolution of China's early design system.
\end{abstract}

\section{Keywords: Republic of China, Shanghai, placard design, evolution}

\section{INTRODUCTION}

During the period of the Republic of China, Shanghai began to use various advertisement methods and forms more frequently and maturely in the commercial development after experiencing social changes and economic transformations in the late 19th century and early 20th century. Among them, modern placards and advertisements became one of the main means of publicity against the background of Western design, and they were combined with the original traditional placards. Their design form, content, and expression methods continuously evolved, and became a unique content in the design system during this period.

\section{THE FORM OF PLACARD DESIGN IN THE EARLY REPUBLIC OF CHINA}

In the form of outdoor advertisement in the early Republic of China, placard advertisement was a longestablished form. Because its procedures are simple and convenient, it already appeared no matter in the city or in the villages and towns, such as "Vaccination Well", "New Open Shop Bone" and so on. However, in the early days, these placards were simple in content and crudely produced. They were rarely used by more powerful industries and businesses, and their social impact was not large. However, when this form developed in the early Republic of China, under the influence of the Western commercial economic form, it gradually evolved into the form of placard advertisement in modern China in combination with the placard form imported from the West. In Xu Baiyi's article "The Development and Origin of Outdoor
Advertisement", he mentioned that, in the development process of modern foreign outdoor advertisement, outdoor advertisement was widely used in the middle and late 19th century. With the invention of lithography at that time, placard advertisement including posters became popular for a while, forming a special placard advertisement era. ${ }^{1}$ In the United States, which had an obvious influence on the design of outdoor advertisement in China at that time, placard advertisement was very popular in the early 20th century. In 1912, the United States organized the "placard Practitioner Association", which was the first national organization of advertisement practitioners in the United States. They created a collage of 24 placards from the original scattered placards in the United States. The placard advertisements were pasted together in this way, with a certain sense of order. ${ }^{2}$ This form of placard advertisement in the United States was recognized and accepted in Shanghai during the Republic of China ("Fig. 1", "Fig. 2"). British American Tobacco used multicolored lithographs to place largescale placards on billboards in major cities in China to attract attention. ${ }^{3}$ Of course, the development of placard advertisement during the Republic of China was also inseparable from the progress of printing

\footnotetext{
Xu Baiyi: "The Development and Origin of Outdoor Advertisement" [J]. Decoration, Issue 03, 1992, pp. 5-7.

2 Xu Baiyi: "The Development and Origin of Outdoor Advertisement" [J]. Decoration, Issue 03, 1992, pp. 5-7.

Shanghai General Annals·Professional Annals·Shanghai Daily-use Industrial Products Business Annals.The Twelfth Advertising Business.Chapter Two Outdoor Advertising.Section 1 [DB/OL] http://www.shtong.gov.cn/node2/ node2245/node66046/node66062/node66243/node66247/userobject1 ai61843.html2008-7-21.
} 
technology and paper technology at that time: Since the beginning of the 20th century, lithographic printing changed from monochrome lithography to color lithography and photolithography; direct printing from lithography to direct printing of metal printing, and then to indirect printing by eraser presses was an important stage in the history of the development of lithographic printing, which was of great significance to the development of paper-based placard advertisement.

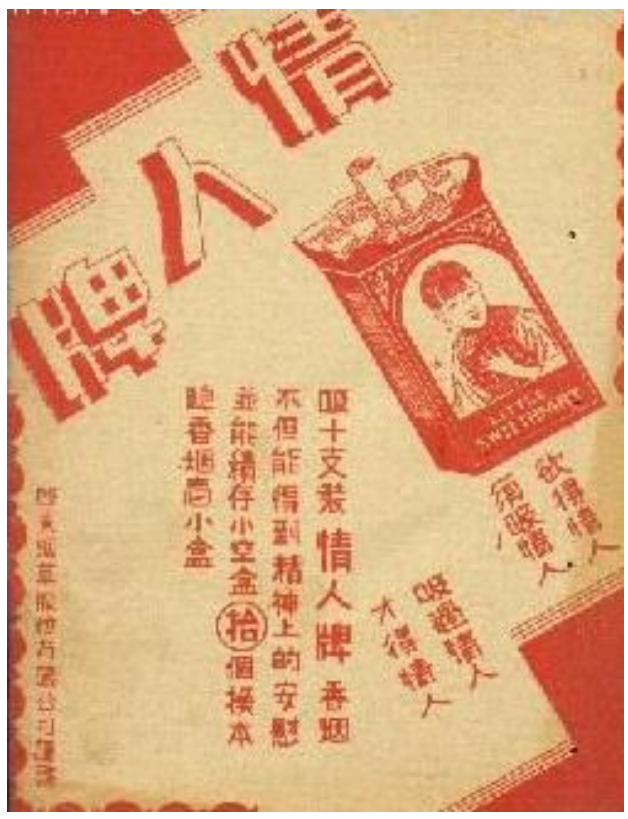

Fig. 1. The placard advertisement of "Sweetheart" cigarettes.

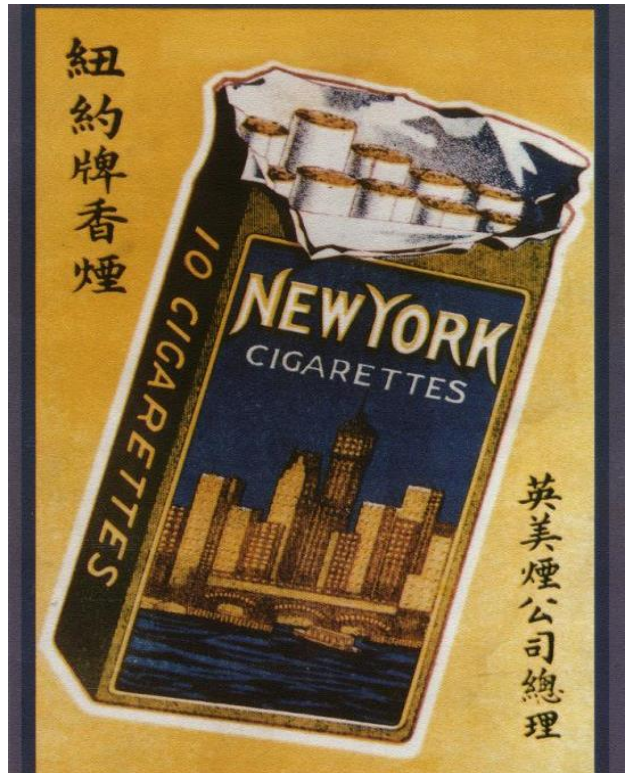

Fig. 2. The placard advertisement of British American Tobacco's "New York" cigarettes.
During the evolution of the overall design of placard advertisement in Shanghai during the Republic of China, the early placard advertisement could only be produced in general print advertisements due to technical constraints. The materials and colors were relatively simple and rough. However, with the maturity of printing technology, the reduction of costs, the intensification of commercial competition, and the improvement of the aesthetic and cognitive level of the audience, many merchants began to apply more refined and colorful forms to their placard advertisement. Many advertisements that were originally only used for more refined advertisement, such as the design and painting of calendars, gradually shifted to outdoor placard advertisement. In the process of transformation, it can be seen that the placard design of the early Republic of China was more focused on characters or story-based themes, and adopted a way of preferring content to products, obviously with the design style of early calendars. A large area of the picture was filled with characters or story paintings, while commercial advertisements were limited to one-line words descriptions or appeared only in the corners of the picture. Although the placard advertisement at this time was also highlighting the decorative function of the picture, in order to attract more target audiences, the overall layout and design of the product promotion control and design planning still focused on highlighting the main character. The product itself was only for service or subordinated to publicity.

\section{THE DIVERSITY AND CONNOTATION OF PLACARD DESIGN IN THE MIDDLE PERIOD OF THE REPUBLIC OF CHINA}

With the enhancement of commercial awareness and the maturity of commercial design, the design of placard advertisement in the 1920s and 1930s gradually got rid of the framework of borrowing from other original designs, and began to embark on a "thinking" that was relatively independent and adaptable to commercial requirements. In addition to paying more attention to highlighting "commerciality", the placard advertisement of this period began to organically integrate the form of the design and the picture with the product. The exquisiteness and novelty of the product itself in the placard advertisement picture became an important means of attracting and promoting products. The characters in the picture gradually became the affiliation of the commodity, and were no longer the core element of the picture, but became the "exhibition appliance" that appeared after the commodity was displayed. For example, the "Sweetheart" cigarettes of Heping Industrial Co., Ltd. were fully equipped with all the elements of modern graphic design and the rudimentary form of the composition method, abandoning elements such as portraits, and placing the image of the product itself in the center of the picture. 
The importance of brand text and promotional language appeared in turn. The design form transforms the original foil. The placard advertisement of British American Tobacco's "New York" cigarettes was also a typical example: There was no annual calendar for the entire placard advertisement. The appearance of the central object (cigarette case) of the placard design abandoned the image of characters not closely related to the product itself, and highlighted the product itself. These advertisement designs started from the perspective of the product's own publicity, completely highlighting the product's own product attributes, and getting rid of the old-style set pattern of calendars. The product itself was completely used as the main body of the picture, making the product itself the main content of the placard. "The White-Golden Dragon" cigarette of Nanyang Brothers Tobacco Company was another similar example: On its own placard advertisement, there were words such as "Chinese people should smoke Chinese cigarettes", "Revitalizing Domestic Products", "It is better not to smoke cigarettes; if you want to smoke cigarettes, please use the Great Wall Brand of domestic products". "The White-Golden Dragon" cigarette placard advertisement not only highlighted the main product in form, but completely ignored the characters, and paid more attention to the product itself instead ("Fig. 3"). After breaking away from the original advertisement design form, emerging outdoor advertisement design forms and design concepts quickly became popular. The combination of composition, shadow, perspective and modern typesetting produced by the Western modern times became a popular trend in placard design at that time. Another example was the design of the "Yapur" bulb advertisement (1934) at that time ("Fig. 4"). In the placard advertisement, there was the publicity of the product itself, the name of the product brand, the company's address, contact information, the advertisement language, and the composition method with obvious modern constructivism. The main composition of the picture from the bottom left to the top right was combined with the decorative figures on the top left, and the light and projection from the light bulb were well and ingeniously combined with "Yapur". The design of advertisements at this stage had obvious modernized design forms and attributes of product image promotion. It was no longer a simple "matching of graphics and text" to attract audiences. The application and development of design elements were already very mature.

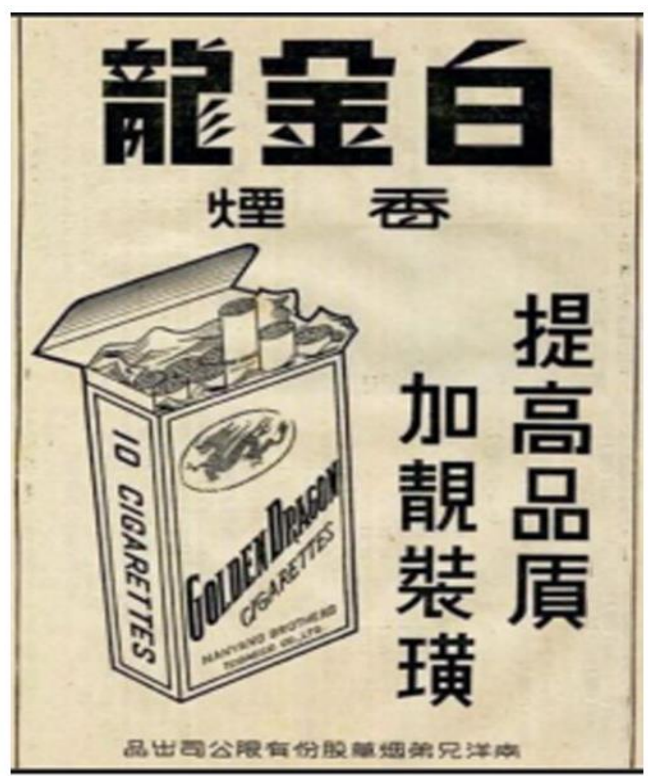

Fig. 3. "The White-Golden Dragon" cigarette advertisement of Nanyang Brothers Tobacco Company.

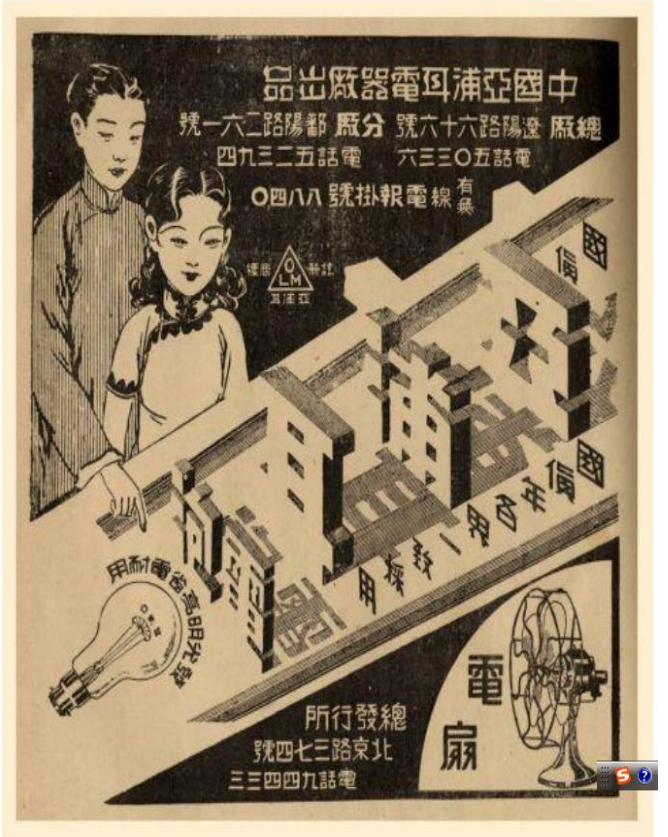

Fig. 4. The "Yapuer" bulb advertisement in Shanghai during the Republic of China.

In the middle and late period of the Republic of China, the design of placard advertisement transformed from a simple propaganda into a product concept transmission, from early simple production to sophisticated printing, and from simple arrangement of image-text content to a design with modern thinking, highlighting the specificity and subjectivity of the product itself more. These changes were also confirmed 
in the "advertisement Psychology" related to the design of placard advertisement during the Republic of China: "According to our habit of reading advertisements, reading advertisements with special fonts is not as easy to understand as reading common 'fonts'. If the advertisement is posted at a distance, the text on it will be difficult to distinguish. If the text on it is in a common font, people can also guess its meaning according to the font. ${ }^{4 "}$ These ideas and methods applied to print advertisements were not only applicable to print advertisements, but also to the production of billboards.

In this interactive process, placard advertisements were released and functionally corresponded to the characteristics of Shanghai's commercial operations during the Republic of China, serving different industries and product categories; however, in the middle and late period of the Republic of China, according to the application characteristics of placard advertisement and the development of commercial content and entertainment consumption, it was reflected as a kind of content "flow". Its corresponding content was not static, and it evolved into another unique form of placard advertisement in the proprietary industry movie posters.

\section{THE DESIGN OF MOVIE POSTERS IN THE REPUBLIC OF CHINA}

In the middle period of the Republic of China, with the introduction of the modern image technology of film, especially after the film became the most widespread and common entertainment method in the middle and late period of the Republic of China, placard advertisement began to be applied to the promotion of films, and there was an inevitable followup. Due to the effectiveness and periodicity of the film, in order to attract the audience to understand the release information in a short period of time, the film needed a large number of advertisements to inform the public about its release period and content. The printing, publishing speed and cost advantages of placard advertisement inevitably made it the main form of publicity for entertainment products in this category, and it had a rare combination of advantages. Movie posters were different from general merchandise. Several parts of the movie placards were relatively fixed, such as the release date, location, film company, main actors and actresses, and movie titles. Regarding the poster's proper name, there was still a distinction. ${ }^{5}$

\footnotetext{
Iseki Jujiro (Japan), trans. by Tang Kaibin: "Advertising Psychology" [M]. Shanghai: Commercial Press, 1925,11, p. 51.

Some scholars believe that "placard is a form of posters, which is very closely related to advertising. There are different differences between commercial placards, cultural placards, political placards, and custom placards. It has gradually become a form of design with great independent value. The social functions and
}

As far as the content of poster design was concerned, placard advertisement were more focused on actual products and brands, while movie posters highlighted movie stills and studios. In this way, movie companies could also post a large number of placards to show publicity before new films were released. For example: "Whenever a new film is released, the Star Film Production Company also posts posters following the example of Peking Opera. Feng Xizui, who has a relationship with the Company, sets up the Great China advertisement Agency, which specializes in advertisement placards." 6 In the Republic of China, movie posters, as a form of development and evolution of placard advertisement, became a unique form in terms of production content, and also provided a more complete and detailed type for the development of overall outdoor advertisement. But from the perspective of design nature, placards and posters were both used for product promotion, but the carrier was different. However, there were many similarities in the design elements, techniques, composition, and modeling of the two, which together constituted all aspects of the placard advertisement during the Republic of China.

\section{CONCLUSION}

Placard advertisement and posters, as printed matters for outdoor use mainly on paper media during the Republic of China, were the most direct beneficiaries of the development of printing during that period. Every advancement in printing technology can bring about an advancement in the production of placard advertisement. This large-area, black-andwhite, chromatic, and multicolored printed Western merchandise placard spreading across the streets and alleys of the city is also an "induction" to guide the audience into modern life. In this period, the placard advertisement has changed from a simple commercial subordination to a modern graphic design under the state of modern industrial and commercial art and modern advertisement. In this kind of consciousness of modern advertising design, a partial conclusion may be drawn: From the perspective of graphics, communication and the integration of Eastern and Western cultures, modern thinking has penetrated into the lives of ordinary people through the intuitive feelings on placard advertisements, and changed

intentions of placards are very obvious, especially in the Chinese society of the 20th century. According to the different needs of war years, political periods, and economic activities, one after another waves are formed." - Zhao Nongbian: "A Brief History of Chinese Art Design" [M]. Shanghai, People's Fine Arts Publishing House, 2012,09, p.196.

6 Ping Jinya, Chen Ziqian: "Shanghai Advertising History" [A]. Shanghai Municipal Museum of Literature and History, Shanghai Municipal People's Government Counselor's Office of Historical Accounts Working Committee: Shanghai Local History Materials (3) [C]. Shanghai Academy of Social Sciences Press. Issue 1, 1984,07, p. 137. 
people's life concepts and lifestyles. In this sense, outdoor advertisement has also played a certain traction role in the process of modernization and early design development.

\section{References}

[1] Xu Baiyi: "The Development and Origin of Outdoor Advertisement" [J]. Decoration, Issue 03, 1992. (in Chinese)

[2] (Japan) Iseki Jujiro, trans. by Tang Kaibin: Advertising Psychology [M]. Shanghai: Commercial Press, 1925,11. (in Chinese)

[3] Ping Jinya and Chen Ziqian: Shanghai Advertising History [A]. Shanghai Municipal Museum of Literature and History, Shanghai Municipal People's Government Counselor's Office of Historical Accounts Working Committee: Shanghai Local History Materials (3) [C]. Shanghai Academy of Social Sciences Press. Issue 1, 1984,07. (in Chinese)

[4] Zhao Nongbian: A Brief History of Chinese Art Design [M]. Shanghai, People's Fine Arts Publishing House, 2012,09. (in Chinese)

[5] Tian Guoqing. The Past in Old Advertisements [M]. Shanghai: Shanghai Far East Publishers, 2010,01. (in Chinese)

[6] Qin Qiwen. Research on Modern Chinese Enterprise Advertising $[\mathrm{M}]$. Beijing: Intellectual Property Publishing House, 2010,08. (in Chinese)

[7] Lv Chao. Heterotopia on the Sea - The Image of Shanghai from the Perspective of Western Culture [M]. Harbin: Heilongjiang University Press, 2010,11. (in Chinese)

[8] Lin Jiazhi. Commercial Art History of the Republic of China [M]. Shanghai: Shanghai People's Fine Arts Publishing House, 2008,01. (in Chinese)

[9] Xin Ping. Discovering History from Shanghai: Shanghai People and Their Social Life in the Process of Modernization [M]. Shanghai: Shanghai University Press, 2009,01. (in Chinese)

[10] Huang Yutao. Research on Commercial Advertising in the Republic of China [M]. Xiamen: Xiamen University Press, 2009,05. (in Chinese)

[11] Zhao Chen. Chinese Advertising History [M]. Beijing: Higher Education Press, 2005,10. (in Chinese) 